\title{
Pleural mesothelioma in a non-shipyard electrician
}

\author{
M Huncharek, J Muscat
}

Secondary asbestos exposure in the workplace is becoming an increasingly recognised health hazard. The existence of a possible risk among electricians in general, and non-shipyard electricians in particular, has received little attention..$^{1-3} \mathrm{We}$ describe a case of pleural mesothelioma in a non-shipyard electrician associated with occupational exposure to asbestos.

\section{Case report}

A 38 year old white man was admitted to another hospital with left sided pleuritic chest pain with effusion (January 1974). Two previous episodes of pleurisy with effusion had occurred in March 1972 and November 1973, both of which cleared spontaneously. Both episodes were of unknown aetiology. The patient denied any weight loss, chills, fevers, cough, haemoptysis, or abdominal or joint pain associated with the effusion. His medical history included pneumonia at ages 10 and 18 and anaphylaxis after an intravenous pyelogram in 1974 . Results of sputum and skin tests for tuberculosis were negative. A 45 pack-year smoking history was noted.

In April 1974 a thoracotomy was performed during which dense broad adhesions were found in the pleural space. Nodules were removed from the diaphragm, left lung, and pleura, and pathological analysis showed ". . . papillary masses of mesothelial cells ... infiltrating skeletal muscle." The tumour was tested with thio-tepa and BCG.

Interestingly, the patient was essentially asymptomatic until June 1982 when pleuritic chest pain recurred with weakness and weight loss. Needle aspiration of the pleural space "produced malignant cells consistent with mesothelioma." $\mathrm{He}$ was given radiotherapy and adriamycin. He did well until August 1983 when he was readmitted to hospital with increased left chest pain and malaise. Pronounced progression of the mesothelioma in the left lung was noted. The right lung was clear.

Boston University School of Medicine, Boston, Mass, USA

M Huncharek

American Health Foundation, New York, NY

J Muscat
Our records indicate that this patient was last known to be alive as of April 1984. We have been unable to locate the patient or his family to determine his vital status.

Concerning his occupational history, he had worked as an electrician from 1959 (age 22) until his diagnosis of mesothelioma in 1974. (From 18 to 22 he was in military service.) He reported working in buildings where acoustic insulation was sprayed on and also did electrical work in locomotives where boilers were being insulated. In 1971 he became employed as a maintenance electrician at an airport and reported being in contact with old asbestos insulation and fire proofing in this capacity. $\mathrm{He}$ stated that insulators and other coworkers would often remove asbestos insulation in his presence.

Several studies have examined deaths from asbestos related lung cancer among shipyard electricians showing an increased risk for this disease. ${ }^{45}$ Although non-shipyard electricians are known to have an increased risk of lung cancer, the risk of mesothelioma in this setting has received little attention. The case presented here suggests the possibility of the existence of a risk of an asbestos related mesothelioma among members of this occupational group. Increased surveillance of these workers may be justified.

1 Quinn MM, Kriebel D, Buiatti E, et al. An asbestos hazard in the reprocessed textile industry. Am J Ind Med 1987;11:255-66.

2 Baker EL, Dagy T, Greene RE. Respiratory illness in the construction trades. I. The significance of asbestos-associated pleural disease among sheet metal workers. J Occup Med 1985;27:483-9.

3 Huncharek M, Smith K, Milatou R. Malignant mesothelioma in a nuclear engineer. $\mathrm{Br} J$ Ind $\mathrm{Med}$ 1988;45:498-9.

4 Newhouse ML, Oakes D, Wooley AJ. Mortality of welders and other craftsmen at a shipyard in NE England. Br J Ind Med 1985;42:406-10.

5 Hodgson MJ, Parkinson DK, Sabo S, et al. Asbestosis among electricians. J Occup Med 1988;30:638-40.

Accepted 10 April 1989 